\title{
Title: Building defect detection: External versus internal thermography
}

Authors:

- Matthew Fox (a) (Corresponding Author) email: matthew.fox4@plymouth.ac.uk Phone number: +447957471025. Postal address: Room 301, Roland Levinsky Building, Drake Circus, Plymouth, Devon, PL4 8AA

- Steve Goodhew (a) email: s.goodhew@plymouth.ac.uk

- Pieter De Wilde (a) email: pieter.dewilde@plymouth.ac.uk

a, Environmental Building Group, Plymouth University, Roland Levinsky Building, Drake Circus, Plymouth, Devon, PL4 8AA, United Kingdom

\begin{abstract}
Many buildings suffer from defects in the building envelope, such as missing insulation, thermal bridging, cracks and moisture problems. Thermography is one technology that can help to identify such defects. However, there are different approaches towards assessing the building envelope. Pass-by thermography is an emerging method, which is used to capture single thermal images of external building elevations. Compared with traditional walk-through thermography, it is much quicker and cheaper to perform. Yet it is currently unclear how successful this methodology is at detecting building defects. This paper qualitatively compares pass-by thermography and walk-through thermography. A set of 122 residential dwellings in South West England was inspected using the both methodologies. Results show that substantially more defects were detected using walk-through thermography, with internal inspections yielding the greatest number of detected defects. Significant constraints with walk-past thermography were identified, such as unknown occupancy behaviour, transient climatic conditions, fixed viewing angles and spatial resolution limitations, which were all found to have a greater impact on image results than during walk-through thermography.
\end{abstract}

Although trends in conductivity defects were found from target comparison analysis between similar dwellings, viewing single external elevations under walk-past thermography was found to miss many different defect types, which would have normally been discovered during traditional walk-through thermography.

\section{Key Words}

Defect detection; Thermography; Walk-through; Walk-past.

\section{Introduction}

Thermography is used to quickly detect thermally significant defects and heat loss from the built fabric and thus is uniquely placed to help tackle increased energy use, fuel poverty and thermal comfort issues. Traditional methods of inspection using this technology comprise of thermographers walking around a building recording images. Under this methodology, a number of significant limitations to building thermography (such as transient climatic conditions, emissivity variations and camera operation) exist, which require expert 
knowledge to accurately interpret the thermal patterns and apparent temperature readings captured in the thermal image. With smaller cameras, the emergence of the digital movement, increased portability, lowering costs, and the introduction of uncooled microbolometers in the 1990s [1], thermal cameras have become much more commercially focused in recent years [2].

Recently, new passive (using natural heat sources and boundary conditions such as solar radiation, air movement and atmospheric temperature [3]) building thermography methodologies have been developed and used as an alternative to traditional walk-through thermography [4]. By carefully selecting the most appropriate methodology, some of the known limitations can be mitigated. One example is the application of time-lapse thermography, which allows to observe climatic and material transient changes over prolonged periods of time [5]. This in turn enables the observation of defect patterns over-time, allowing for enhanced interpretation.

Another new methodology is pass-by thermography, where single external elevations of buildings are imaged over short time periods. At present this approach is not well known and only recently beginning to be applied in practice.

It is important that new methodologies are compared with those that are commonly used so that a deeper understanding of application and limitations can be made. This view is predicated on comments by some thermography researchers, who warn about the risk of defect misinterpretations from images collected using pass-by thermography. For instance, Schwoegler [6] suggests how drive-by thermography (a form of pass-by thermography) will face limitations to image interpretation due to emissivity variances, changing view angles, thermal mass variations and unknown occupancy habits.

This paper explores the suggested strengths and limitations to pass-by thermography in comparison with traditional walk-through thermography on residential dwellings in Devon and Cornwall, England.

\section{Current building thermography approaches}

\subsection{Traditional Walk-through thermography}

The most commonly used passive building thermography methodology is walkthrough thermography, also known as the 'traditional' method [4]. This methodology is outlined by the American Society for Testing and Materials (ASTM) [7], the Residential Energy Services Network (RESNET) [8] and British Standard BS EN 13187:1999 [9] and involves the thermographer walking around the building examining all external building components from both the internal and external sides. Utilising the benefit of real time feedback [10], the thermal camera is used to systematically scan all building surfaces looking for any potential thermal anomalies [11]. Upon viewing a thermal anomaly, the thermographer then records a thermal image for analysis and possible inclusion within a report [7]. 
There are however certain climatic requirements that need to be met for thermographic analysis. Pearson, [12], UKTA [13] and the British Standard for qualitative thermography [9] are a selection of sources that list the key climatic requirements for conducting thermographic surveys. These include:

- Wind speeds lower than $5 \mathrm{~m} / \mathrm{s}$;

- At least $10^{\circ} \mathrm{C}$ temperature difference between internal and external spaces;

- Surfaces free from direct solar exposure both during the survey and in the hours preceding the survey;

- Undertaken during cloudy conditions to avoid reflecting a clear sky.

Because of these requirements, in cool maritime climates similar to the UK this means that thermographic inspections are often undertaken during the cooler months (October to March) of the year and during the coolest part of the day (during the hours of darkness). This latter issue is further restricted by the need to gain access to dwellings, limiting inspections to sociable hours in the evening/night time.

Traditional thermography affords the opportunity for detailed thermographic analysis of buildings where potential defects can be viewed from many different angles and distances. Also the results from this methodology can be used in combination with other techniques, such as air-tightness testing, to enhance airleakage detection [14] and computer simulation, which can enhance defect understanding through comparison with thermal models $[15,16]$. However this walk-through thermography can be time-consuming, especially in buildings with many rooms [17]. Smale [18] indicates that a single dwelling walk-through survey might take between 60 and 150 minutes to complete, with more lengthy periods expected for non-domestic buildings. With increased time comes increased cost and this is reflected in the price charged for a single traditional thermographic survey. For example, one UK based company charges between $£ 275$ (1-3 bedroom dwelling) and $£ 475$ (5 bedroom dwelling) per survey [19].

\subsection{Street Pass-by thermography}

Given the timescales and costs involved in traditional thermographic surveys, there has recently been a drive to reduce both of these factors. One methodology in particular, pass-by thermography has been developed to speed-up the inspection process in order to survey many more building in one survey period.

One form of pass-by thermography currently being explored uses vehiclemounted thermal cameras to survey residential streets [20-22]. The cameras used capture high-resolution thermal images of each dwelling's front elevation as it passes by. This methodology appears similar to that used by Google Streetview [23] for street photography and is referred to as a drive-by approach [20].

It is clear that driving past buildings with a thermal camera will permit a larger number of properties to be surveyed during the same survey period of traditional walk-through thermography. In addition, pass-by thermography does not require access to dwellings, so occupants do not need to be home. This 
means that such thermographic inspections can be undertaken outside of sociable hours when residents are home and awake. This can therefore minimise discrepancies in results between dwellings due to surveying many buildings under similar climatic conditions. Yet, the temporal resolution (sensor refresh rate) and speed at which many modern day thermal cameras are able to record images is not currently sufficient without improved equipment that is currently prohibitively costly for many commercial enterprise. Recent research and development work by MIT and spin-off company, Essess [20-22] has centred on developing a system, which seeks to improve the temporal resolution while maintaining spatial resolution by using multiple thermal cameras, slow driving speeds and image enhancement algorithms, such as their Kinetic Super Resolution process. Whilst findings by Miller \& Singh [22] demonstrated how drive-by thermography could be between 4 and 4.5 times cheaper than the cost of a traditional methodology, some estimates for single elevation pass-by thermography in the UK are as low as $£ 5$ per building [24]. This therefore makes the cost savings for pass-by thermography approximately 55 to 95 times the cost for walk-through thermography.

In the UK, a pass-by approach to thermographic building inspections has been commercially developed and applied on housing association properties. One such example applied single elevation thermal imaging on 30,000 dwellings in Scotland in 2012. The specific details of this methodology have not been published, so only implied assumptions can be made from literature by Clyde Valley Housing Association [25], who were one of the clients having dwellings surveyed. Nevertheless, from internal reports and press releases on this project, it appears that data from these studies has been collected using a walk-past methodology, where a thermographer walks from dwelling to dwelling, thermal imaging the front elevation of each one.

As part of the research undertaken by MIT on drive-by thermography, Phan [20] undertook preliminary walk-past studies of dwellings located in Massachusetts during January 2010. For this research, walk-past surveys were conducted over 7 nights from $6 \mathrm{pm}$ to $2 \mathrm{am}$. Key observations from this work included:

- Each dwelling took approximately 10-15 minutes to survey.

- Between 20-30 homes could be surveyed per night. (this was viewed by Phan as being too slow to scale up to inspect entire towns or cities).

- Working in cold weather conditions was physically demanding.

- Unexpected heat loss from draughts, poor insulation, windows, doors and roofs was discovered.

- Inconsistencies were found in the data from one dwelling to the next.

- Weather (such as rain and snow) affected the quality of the thermal images.

While the objective of the research was to implement a drive-past methodology, Phan undervalued the benefits found from walk-past thermography (such as increased speed compared with traditional thermography), and little was made on the impact that weather can have on data collection/analysis. 
To date, work using pass-by thermography has focused on the quantitative analysis of building thermal performance. For example, overall heat loss, energy use and $\mathrm{CO}_{2}$ emissions. Researchers cite the need to speed up quantitative housing assessment [26] and are using such pass-by methodologies to determine dwelling energy consumption and $\mathrm{CO}_{2}$ emissions [25]. Yet these efforts appear to have not taken into account the common consensus on thermographic limitations such as internal/external temperature differences and climatic variances. Berry [27] offers one critique on quantitative applications of pass-by thermography. He states that total dwelling heat loss cannot be inferred from single elevation thermal images. This is because of numerous uncertainties such as unknown dwelling usage/occupancy, unknown dwelling scale and unknown heat loss from other elevations, all of which will significantly impact upon the actual total heat loss value. Berry also suggested that building façades would perform differently depending on their orientation. This was likely due to differences in wind, solar loading and rain exposure effecting one side of a street more than another.

Furthermore, work undertaken by the authors [5] illustrates the effects that transient climatic changes can have on heat transfer through materials and thermal image interpretation. This therefore raises questions over the ability of a fast methodology to collect meaningful image data that can be used to assess (qualitatively or quantitatively) overall thermal performance and defects in buildings effectively.

As mentioned earlier, some researchers such as Schwoegler [6] and Berry [28] caution against the application of pass-by thermography. Until now, this approach has mainly been promoted by commercial enterprise.

Although the common focus for pass-by thermography has been for quantitative analysis, reflecting upon the comments made by critics of this methodology, and in light of Pearson's [12] caution against undertaking quantitative analysis using external thermography, the work in this paper specifically focuses on qualitative analysis. This also helps to aid cross comparison with walk-through thermography, which is typically conducted using qualitative analysis.

\section{Methodology}

A combined total of 122 dwellings were inspected for the research in this paper. Out of this total, 77 dwellings were inspected using a walk-past methodology and 45 were inspected using a walk-through methodology. The following section lists the methodologies used for both the walk-through and walk-past thermography surveys.

\subsection{The two methodologies}

Walk-through methodology

The walk-through thermography surveys undertaken by the authors of this paper were originally conducted as part of a separate large-scale thermographic survey in Cornwall. This project was called 'Thermal Imaging Cornwall 2013' [29] and formed part of the broader "Cornwall Together Phase 2" project, which was funded jointly by the Eden Project and the DECC (Department of Energy \& 
Climate Change). The objective of this separate project was to understand how thermal images can be best used to communicate energy issues to residents and how these might influence decisions on home improvements. As part of this project, 220 dwellings were inspected using a traditional walk-through thermography methodology. Presented in this paper are the results from 45 of these dwellings. These represent only those personally inspected by the authors of this paper. This is important because it is not practical to make assumptions on the context within which an image has been recorded, such as weather conditions, internal/external air temperatures, emissivity values and reflected sources of radiation etc. Therefore image interpretations will be much harder, with a greater risk of misinterpretation.

The methodology used for the walk-through surveys in this paper followed the principles established by the American Society for Testing and Materials (ASTM) [7], the Residential Energy Services Network (RESNET) [8] and British Standard BS EN 13187:1999 [9].

\section{Walk-past methodology}

Since this project did not have access to vehicle-mounted thermal camera equipment, as used by MIT and Essess in their drive-by thermography work [20, 21], it was not possible to automatically capture thermal images of dwellings from a moving car whilst remaining safe on public highways. Because of this limitation, a walk-past survey was selected to investigate the success of pass-by thermography.

The walk-past thermography methodology used in this paper is a development to the methodology used by Phan [20]. The thermographer walked the survey street, passing each designated dwelling one-by-one, where the thermographer would pause to capture thermal images.

After completing the survey, all dwelling images were positioned on a single sheet next to each other, making it easier for qualitative comparison between dwellings.

\subsection{Case study sample}

\section{Walk-through methodology}

Residents in Cornwall were invited to sign-up for free thermal imaging of their homes as part of the 'Thermal Imaging Cornwall 2013' project, which led to 1001 householders registering interest [29]. Applicants were randomized and selected for thermal imaging. These dwellings were then grouped together into regional areas so that multiple dwelling surveys could be conducted in a single evening. Areas included: Truro, Callington, St Austell, Camborne, Saltash, Looe, Launceston and Penzance.

Great care was made to contact any potentially vulnerable participants to explain before visiting the purpose of the research [30], their rights to consent and withdrawal, and to appreciate any sensitive issues that they might have. Providing free thermal imaging to households experiencing fuel poverty was also viewed as providing an opportunity to potentially contribute towards bringing 
some participants out of fuel poverty [30], by discovering/showing areas of potential (unacceptable) heat loss.

\section{Walk-past methodology}

Four streets in Devon were selected as case studies for walk-past thermographic investigation. Each street comprised of one predominant period of housing construction. A broad range of construction periods were selected, which included: Pre 1900s, 1950s, 1970s and 1990s. Different construction methods were also of interest and dwellings were selected, which represented those typically found in the South West of England were sought and included solid wall masonry, insulated cavity wall and un-insulated cavity wall.

77 dwellings were inspected using a walk-past thermography methodology in this research. The increased number of surveys compared with walk-through thermography ( 45 dwellings) reflects the increased speed of conducting a single survey using walk-past thermography.

Both privately owned and rented housing association dwellings were inspected as part of this research. Private residents were invited to participate by letter or direct communication, and were offered the thermal image as an incentive. A local housing association provided access to rented accommodation.

\section{Sample limitation}

A limitation of the sample selection was the inability to undertake both methodologies on the same dwellings. This was in part due to privacy and confidentiality constraints established during the independent 'Thermal Imaging Cornwall 2013' project, which was undertaken before the walk-past studies. Furthermore, the dwellings inspected during this project were scattered over a countywide area, with few cases being located on the same street. These constraints made utilising the same cases for the subsequent walk-past thermography investigation not possible.

This limitation makes direct comparison between the data from the two studies problematic, however to help mitigate this limitation, results from the walkthrough studies have been split into external and internal inspections. By comparing the data on externally detected defects only from both studies (Walkthrough and Walk-past), common trends in defect detection ability can be inferred.

\subsection{Data analysis}

The methods of qualitative analysis employed for this research included [31]:

- Target signature - Determining the presence and type of potential defect within an elevation or component based on past experience from similar buildings.

- Target symmetry - Assessing different parts of a single elevation to determine / check the presence of potential anomalies.

- Target comparison - Comparing one elevation with other elevations of similar properties to determine the presence and type of defect. 
All recorded thermal images were analysed in detail using the FLIR Tools+ postprocessing software [32] to adjust settings and more easily compare thermal patterns from one image to the next.

To minimise the risk of misinterpreting defects, two level 2 qualified thermographers [33] reviewed the case study thermal images and discussed the likely defect portrayed. Despite this rigour, image analysis remained a source for potential inaccuracies.

Whilst buildings are susceptible to a broad range of building defects [34, 35], thermal imaging is only able to detect those, which induce a thermally significant signature. Balaras \& Argiriou [36] and Walker [31] discuss the following overall groups of thermally significant building defects:

- Moisture ingress. Such as rising damp or water penetration (precipitation or faulty service related).

- Ventilation heat loss. Draughts from gaps around windows, doors and cracks in the building fabric etc.

- Conduction heat loss. Missing or damaged insulation and cold bridging through lintels etc.

- Service faults. Missing or damaged pipe insulation and over heating appliances etc.

For every survey, the case study dwellings were analysed to determine the perceived presence of any of these four thermally significant defects. If a building showed signs of a particular defect group, this was recorded. It is important to note, that the number of defects in one specific group per dwelling was not recorded. Instead, a single record was made for at least one occurrence of that defect group per dwelling.

Because some of the defect groups could be identified in different parts of a building, the incidence of defect group was further split into sub-categories for deeper analysis. These sub-categories stipulated the specific location of a defect, such as in a roof, window, door or wall.

The protocol adopted for categorising defect types, used the commonly accepted pattern characteristics set out by Balaras \& Argiriou [36], RESNET [8], FLIR [37] and BSi [9] who list descriptions of the pattern each defect most commonly displays:

- Ventilation losses - Fanning and uneven temperature gradients

- Conductivity losses - Defined patches of temperature variation

- Moisture related defects - mottled patchy temperature variations

- Service faults - warm or cool patterns, which clearly denote a service system.

\subsection{Equipment}

A recently calibrated FLIR T620bx thermal camera was used for all of the thermographic surveys in this research. This camera was selected as a top-of- 
the-range model at the time of this study. Figure 1 provides technical specifications for this camera.

\begin{tabular}{ll}
\hline IR resolution & $640 \times 480$ pixels \\
Field of view (FOV) & $25^{\circ} \times 19^{\circ} / 0.25 \mathrm{~m}(0.82 \mathrm{ft})$ \\
Spatial resolution (IFOV) & $0.69 \mathrm{mrad}$ \\
Thermal sensitivity (NETD) & $<40 \mathrm{mk}\left(<0.04^{\circ} \mathrm{C}\right)$ at $+30^{\circ} \mathrm{C}\left(+86^{\circ} \mathrm{F}\right)$ \\
Image frequency & $30 \mathrm{~Hz}$ \\
Temperature range & $-40^{\circ} \mathrm{C}$ to $+150^{\circ} \mathrm{C}\left(-40^{\circ} \mathrm{F}\right.$ to $\left.+302^{\circ} \mathrm{F}\right)$ and \\
& $+100^{\circ} \mathrm{C}$ to $+650^{\circ} \mathrm{C}\left(+212^{\circ} \mathrm{F}\right.$ to $\left.+1202^{\circ} \mathrm{F}\right)$ \\
& $\pm 2^{\circ} \mathrm{C}\left( \pm 3.6^{\circ} \mathrm{F}\right)$ or $\pm 2 \%$ of reading \\
&
\end{tabular}

Figure 1. FLIR T620bx thermal camera technical specifications.

To ensure that early images were not adversely effected by sensor acclimatisation (to surrounding atmospheric conditions), the thermal camera was switched on and left for 30 minutes to acclimatise before commencing the survey [1]. For all images the camera emissivity value was set to 0.93 , which aligns closely with the majority of building materials [38]. However care was taken to acknowledge emissivity variances such as metals etc. and the effects from these variances during the analysis of all thermal images.

\subsection{Climatic conditions}

Based on the understanding that weather conditions can have a significant impact upon a thermographic survey, the careful planning of survey dates were choreographed to meet the most ideal conditions. This often meant confirming the survey date with householders only a day or two prior to the survey occurring. Forward planning a survey date with an external client, which met the optimal weather conditions recommended for external thermographic surveys $[9,13]$ proved particularly challenging.

For all case studies, local weather forecasts were observed for at least two days leading up to the start of the survey. Experimentation periods were chosen that minimised the likely presence of clear skies, precipitation and wind, and which had an external temperature that remained at least $10 \mathrm{~K}$ lower than internal air temperatures. If the conditions were forecast to not comply with recommendations set out by the UKTA [13] and the British Standard for qualitative thermography [9] then the survey was postponed or cancelled. The purpose of this exercise was to ensure a period of relative uniformity in climatic conditions prior to the survey in order to have the least impact on materials and camera interference.

All residents were requested to turn their main heating supply on for at least two hours prior to, and left on during the survey [39], with the thermostat adjusted to a suitably high setting above $291.15 \mathrm{~K}$. This would ensure the presence of a suitable thermal gradient between inside and outside, and would make potential defects more apparent. Whilst many of the householders complied with this request, there were some who did not. This was difficult to ascertain during the 
walk-past thermography surveys, since the internal air temperatures were unknown due to the lack of dwelling access.

\subsection{Foreground obstructions}

It was common to find foreground objects obscuring parts of a construction. Objects such as trees, bushes and cars presented external problems, while internally, furniture (sofas and televisions, etc.), curtains and pictures frequently concealed parts of the building. It was rarely practical for case study residents to remove obstructive objects six hours prior to a survey as recommended by FLIR [37]. During the walk-through inspections, obstructions could sometimes be dealt with by using different angles to view concealed elements, though during the walk-past surveys, where a more fixed view was used, it was not always possible to avoid the obstruction (particularly if the obstruction was fixed, such as a bush). This meant that foreground obstructions were recognised as an unavoidable limitation and consequently some defects present might have been missed.

\section{Results}

The following section presents qualitative results obtained from the walk-past and walk-through thermographic surveys.

\subsection{Survey methodology observations}

Walk-through thermography

Each of the 45 dwellings were inspected using walk-through thermography during ten survey sessions that were conducted between February and March in 2013. These were during evening periods that spanned between $6 \mathrm{pm}$ and midnight.

On average, each survey took approximately 40 - 60 minutes to complete. A maximum of $6 \mathrm{dwellings} \mathrm{could} \mathrm{be} \mathrm{inspected} \mathrm{per} \mathrm{evening} \mathrm{period} \mathrm{using} \mathrm{this}$ methodology. Internal inspections took the most time to conduct, comprising on average $75 \%$ of the total survey time to complete compared with external inspections. During each survey, data on air temperature, weather conditions and property information was collected.

Figure 2 presents an example selection of thermal images, which are typical of a traditional walk-through thermographic survey conducted during this research project.
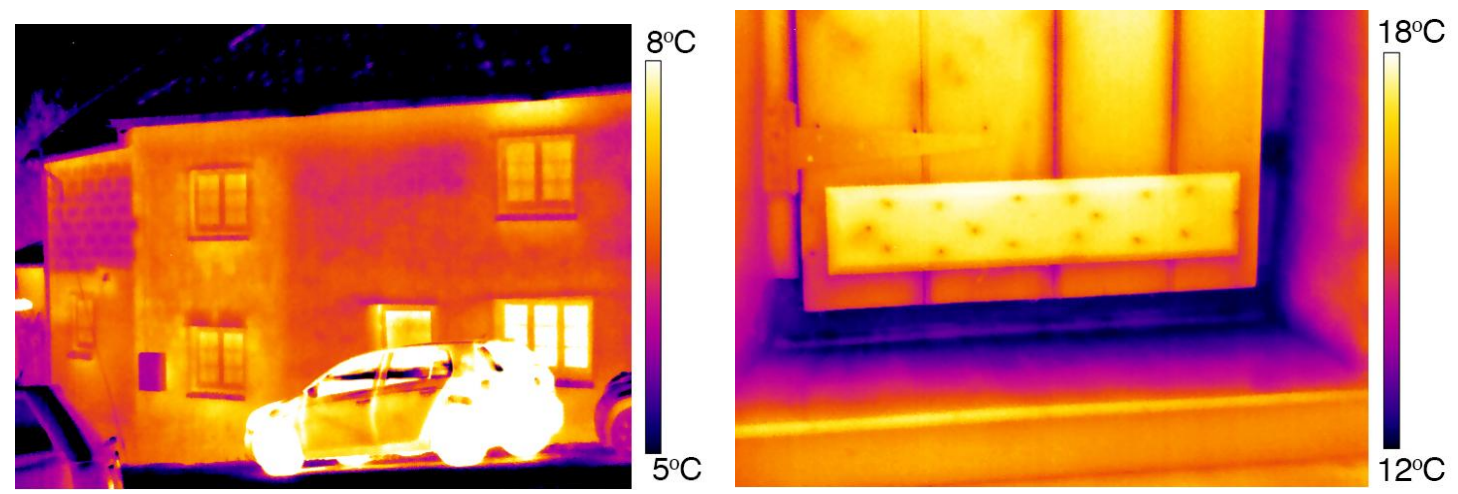

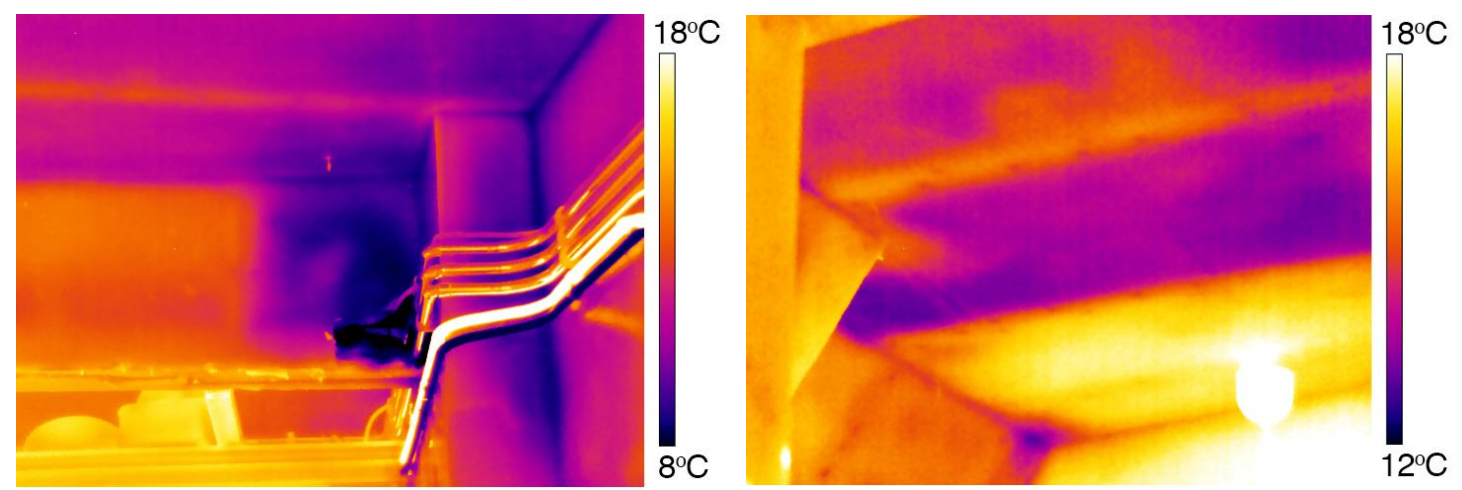

Figure 2. Example of walk-through thermography images.

\section{Walk-past thermography}

Each of the 77 dwellings were inspected using walk-past thermography during four survey sessions that were conducted during March 2014. Each survey took between 7 and 10 minutes to complete per dwelling. Surveys were conducted between the hours of $8 \mathrm{pm}$ and $1 \mathrm{pm}$.

Due to the camera lens having a FOV of $25^{\circ} \times 19^{\circ}$ the thermographer stood no more than $20 \mathrm{~m}$ from a typical two storey dwelling to capture as much of the buildings elevation within one image. This often meant standing on the furthest opposite side of the street to the observed dwelling. However, such distances were not always possible, nor were all dwellings two storeys in height. Consequently, there were some occasions in which the thermographer stood closer to the building and needed to either record images at an angle to the dwelling, or capture multiple images, which were combined into a single larger view of the entire elevation.

Figure 3 presents an example of typical thermal images collected during a walkpast survey, allowing cross comparison between similar dwelling types. 

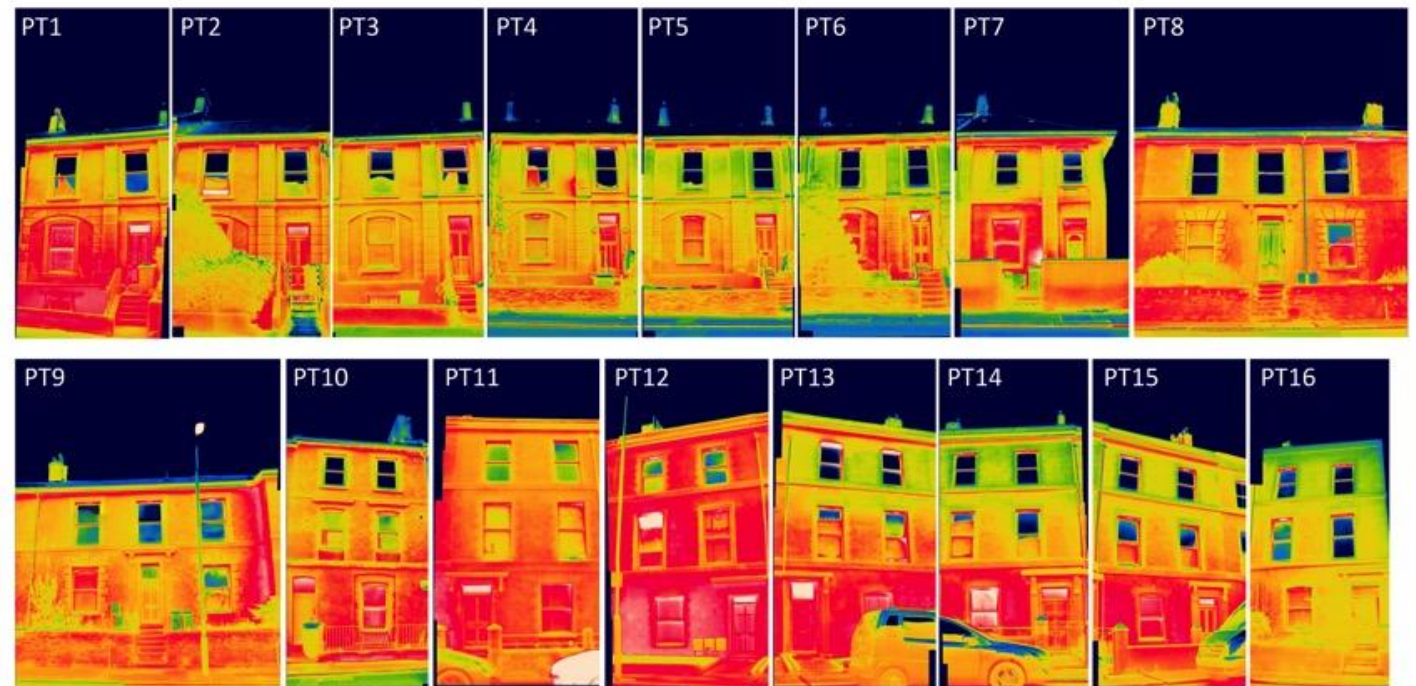

North Street Elevation (PT1 - PT16)

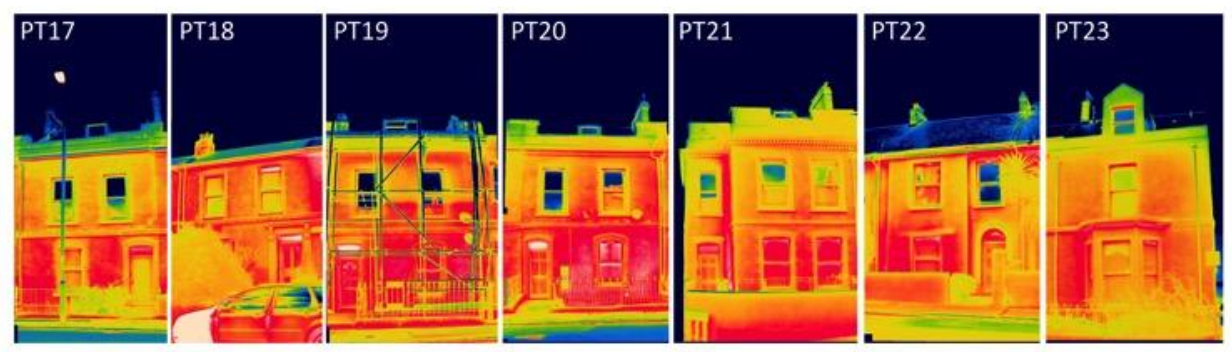

South Street Elevation (PT17 - PT23)

$10.0^{\circ} \mathrm{C}$

Figure 3. Example of walk-past thermography images.

\subsection{Walk-through survey findings}

Overall results from the defect counting exercise showed that $100 \%$ of the buildings inspected using walk-through thermography indicated the potential for one or more thermally significant anomaly. By interpreting the thermal patterns, it was possible to broadly categorise these anomalies into one of four overall building defect groups:

- Ventilation heat loss (Draughts etc.)

- Conduction/cold bridging heat loss (Missing or damaged insulation etc.)

- Moisture related defect (Damp and moisture penetration etc.)

- Service faults (Leaking services etc.)

Of these, the most commonly identified were ventilation and conductivity heat losses (Figure 4). Together, these accounted for almost three quarters (73\%) of the total defects detected using a walk-through methodology. 


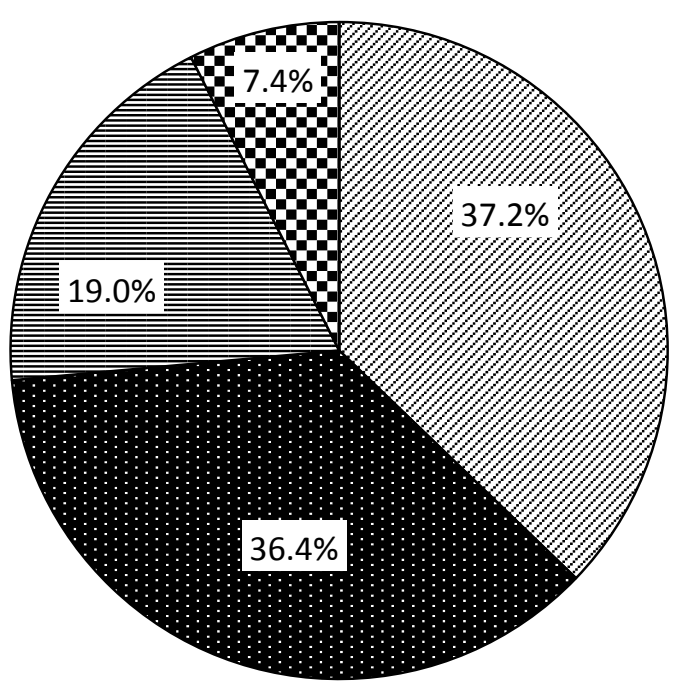

Conductivity defect

QVentilation defect

目Moisture defect

छervice faults

$\square$ No defects found

Figure 4. Proportion of thermally significant building defects (by overall defect group) detected in all walk-through case studies.

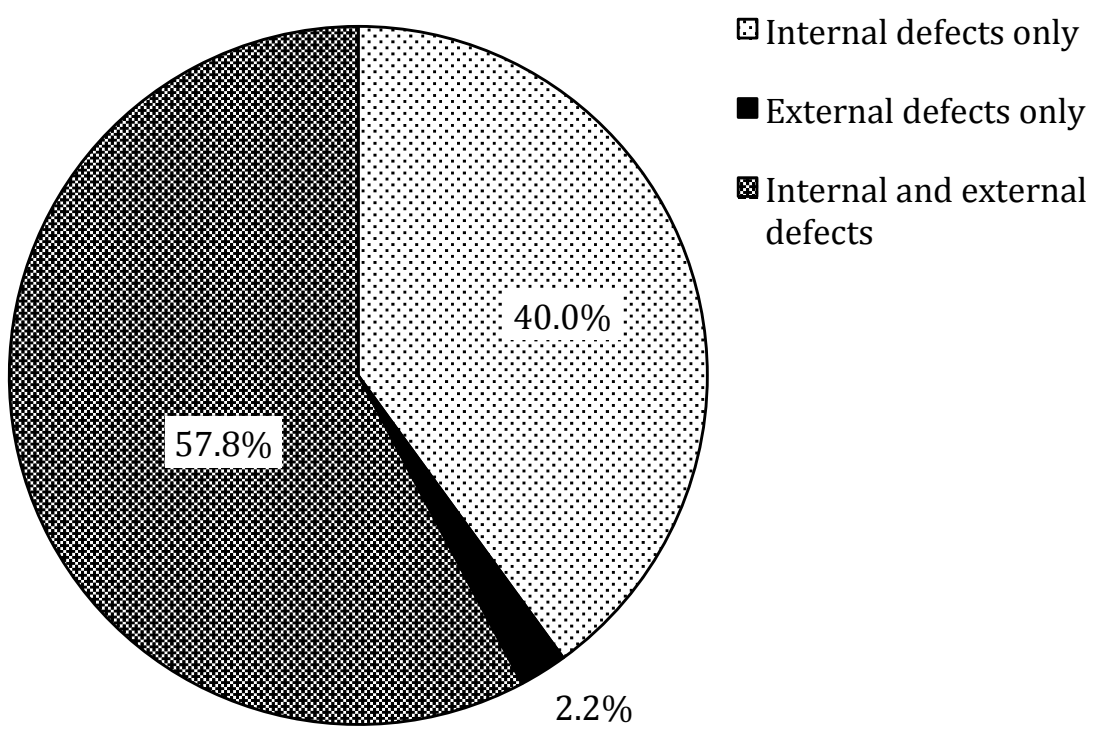

Figure 5. Location of detected defects (internally/externally).

\section{Results by location}

Having performed external and internal thermography as part of the walkthrough inspections, it was possible to further categorise defects into those viewed from the outside (looking at the external surface of a building), and those viewed from the inside (looking at the internal surface of a building). Figure 5 illustrates the percentage of dwellings where at least one potential defect was detected on either the internal, external or both surfaces of the same dwelling.

Of the 45 dwellings inspected, 27 (60\%) exhibited thermally significant defects that could be detected using external thermography. Of all the defect groups, there were only potential signs of conductivity (cold bridging and missing insulation), ventilation (draughts from windows and doors) and service 
anomalies (un-insulated pipes) detected externally. In contrast, analysis showed that 44 out of $45(97.8 \%)$ dwellings inspected presented defects that could be observed using internal thermography, and that all of the defect groups were potentially detected.

Combining data on the location of potential defects with that of the different defect groups, figure 6 shows that for each overall group, defects were more likely to have been detected using internal thermography compared with external thermography. Other observations included noticing that conductivity defects were almost as commonly detected externally as they were internally, also there were no instances of moisture defect detection using external thermography.

Breaking down figure 6 into the defect sub-categories delivered results that specifically showed where internal and external thermography proved most successful. This is illustrated in figure 7.

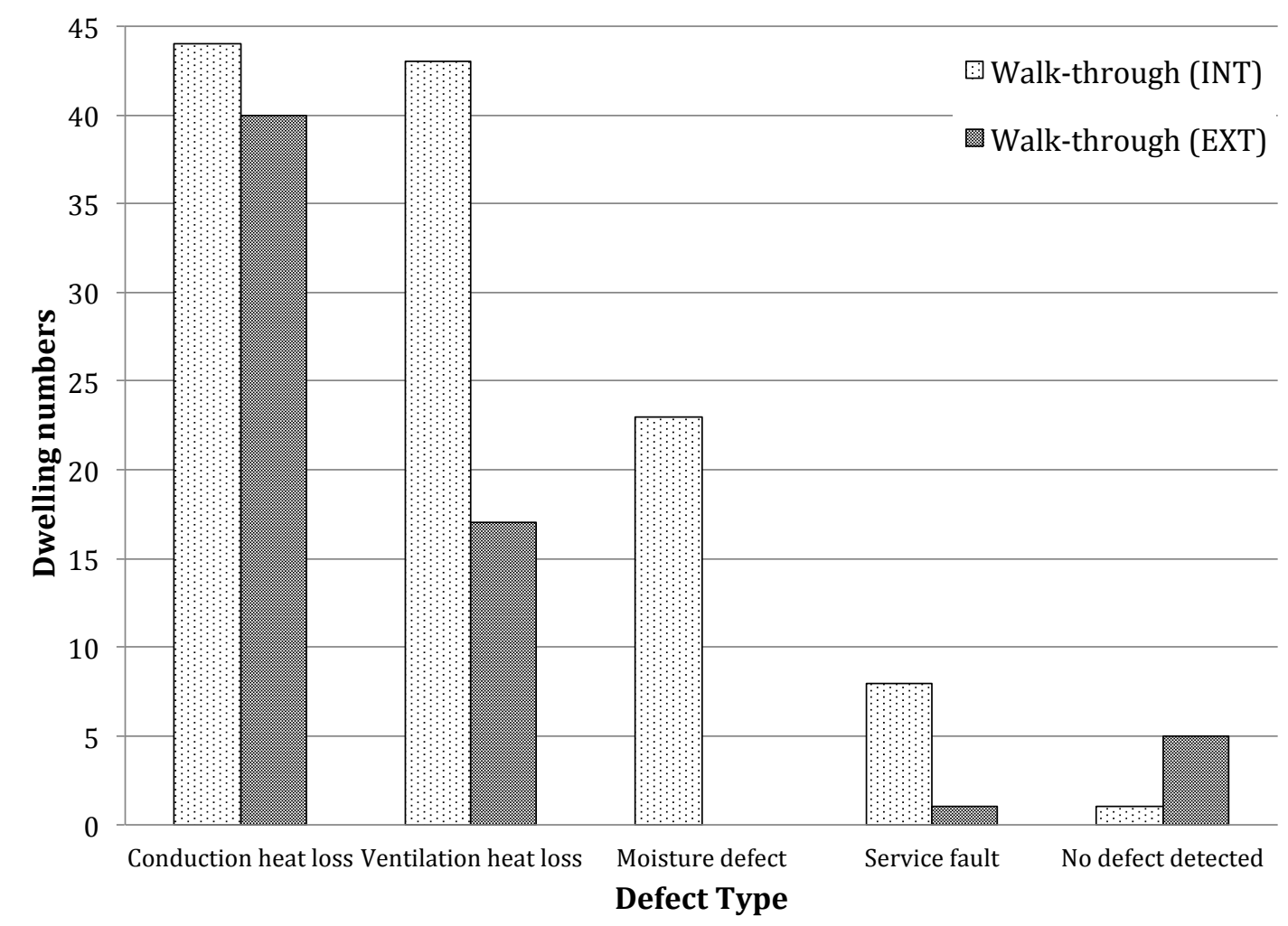

Figure 6. Incidence of thermally significant defect by location and overall group for walk-through thermography surveys. 


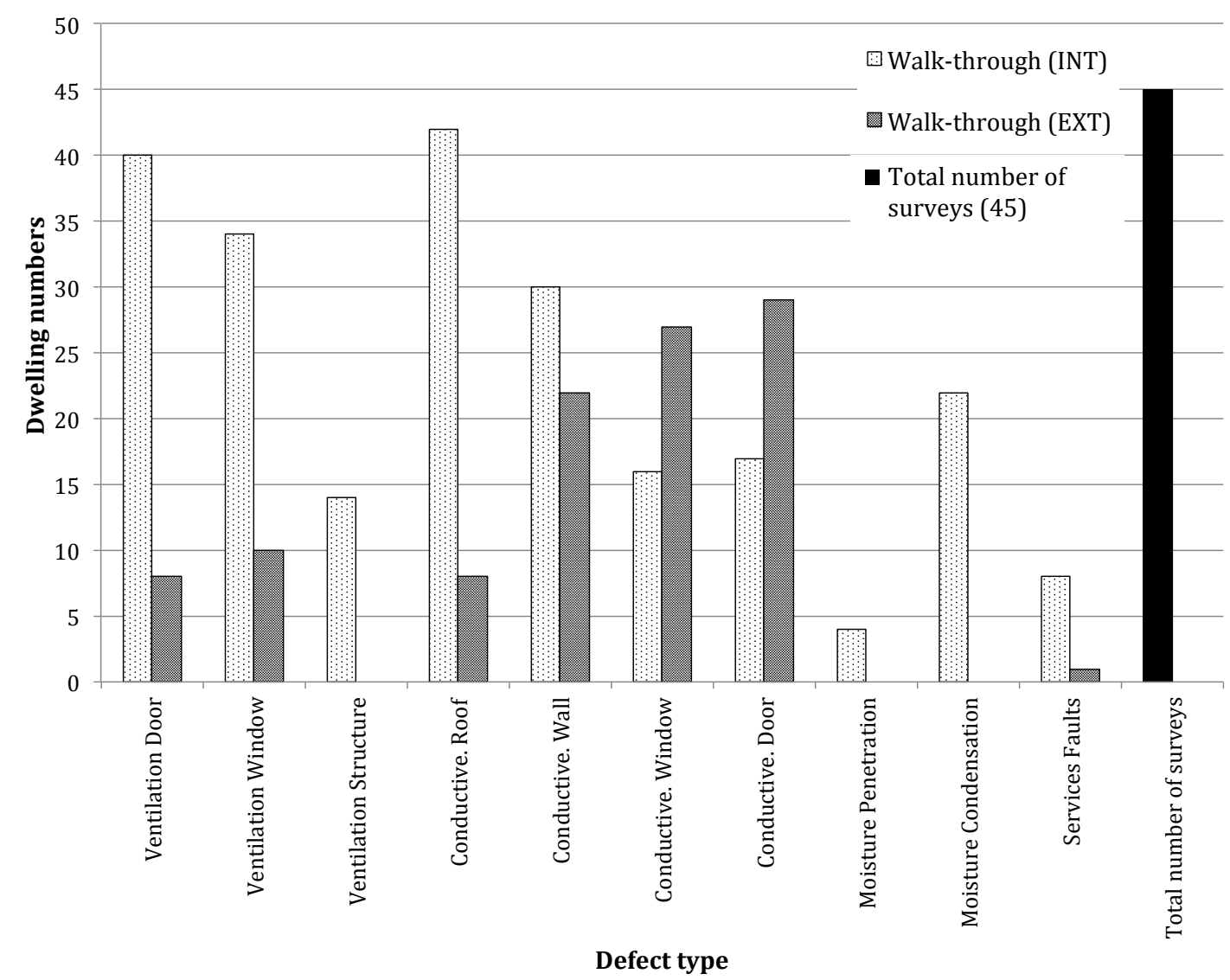

Figure 7. Incidence of thermally significant defect by location and sub-category (Walk-through thermography).

From figure 7, the following observations were made:

- While few ventilation defects were detected using external thermography, none were detected that came from sources other than windows and doors.

- Whilst conductivity defects illustrated in figure 6, appear to be almost as commonly found outside as inside, figure 7 shows that one sub-category, conductivity losses from roofs, performed significantly poorer under external thermography when compared with internal thermography.

- The only two defect sub-categories that were more commonly detected using external thermography compared with internal thermography were conductivity defects from doors and windows.

Another observation from the case study results was that some defects could be detected on both sides of a construction. In all cases however the potential defect was found to be more pronounced and clear when viewed from the inside, as illustrated in figure 8. This aligns with Pearson [12], who states that defects detected using external thermography almost always show more clearly on internal thermography. 

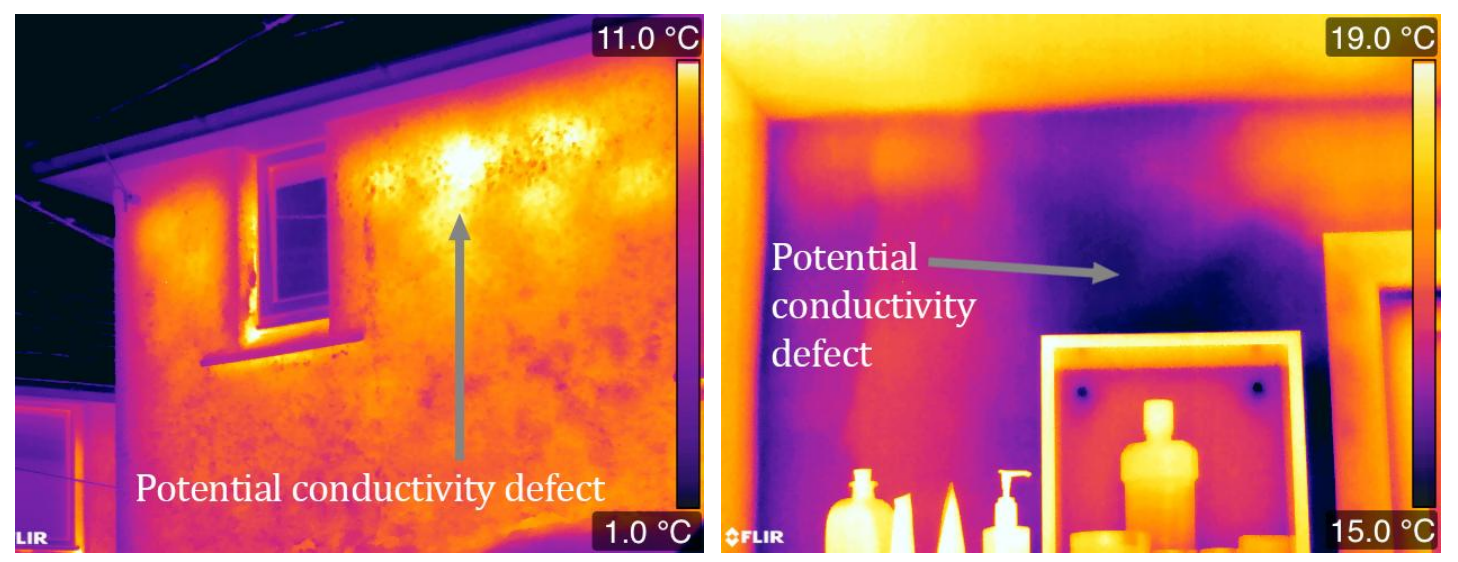

Figure 8. A potential conductivity defect viewed from both sides of the wall.

\title{
4.3 Walk-past survey findings
}

Initial overarching results from the walk-past thermography surveys showed that only $74 \%$ of all dwellings inspected showed signs of potential thermal anomalies (Figure 9). The thermal anomalies detected were characterised as being either ventilation heat loss (Draughts) or conductivity heat loss (Missing or damaged insulation and cold bridging etc.) sources. There were no instances of moisture related anomalies or service faults. Of these, the most commonly identified defect group was conductivity heat loss, which accounted for $55 \%$ of the total defects detected using a walk-past methodology.

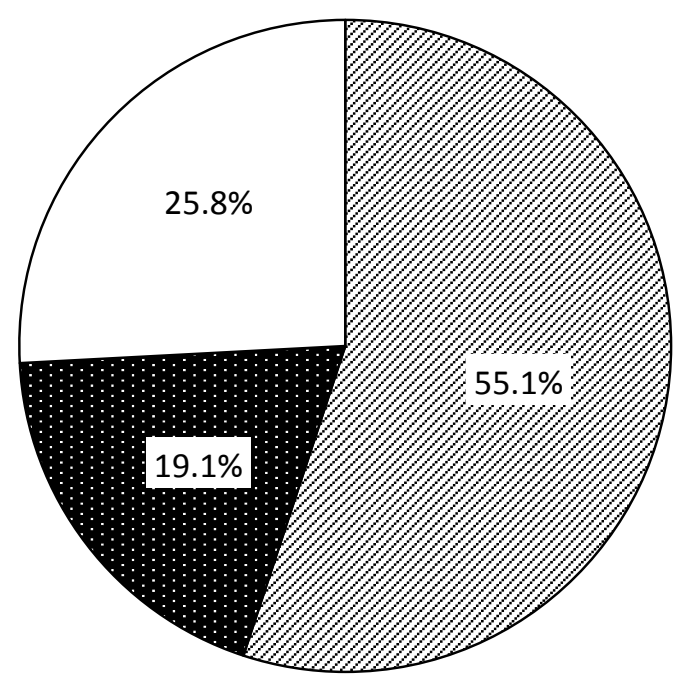

\author{
Q Conductivity defect \\ Ventilation defect \\ $\boxminus$ Moisture defect \\ Service faults \\ $\square$ No defects found
}

Figure 9. Proportion of thermally significant building defects (by overall defect group) detected in all walk-past case studies. 


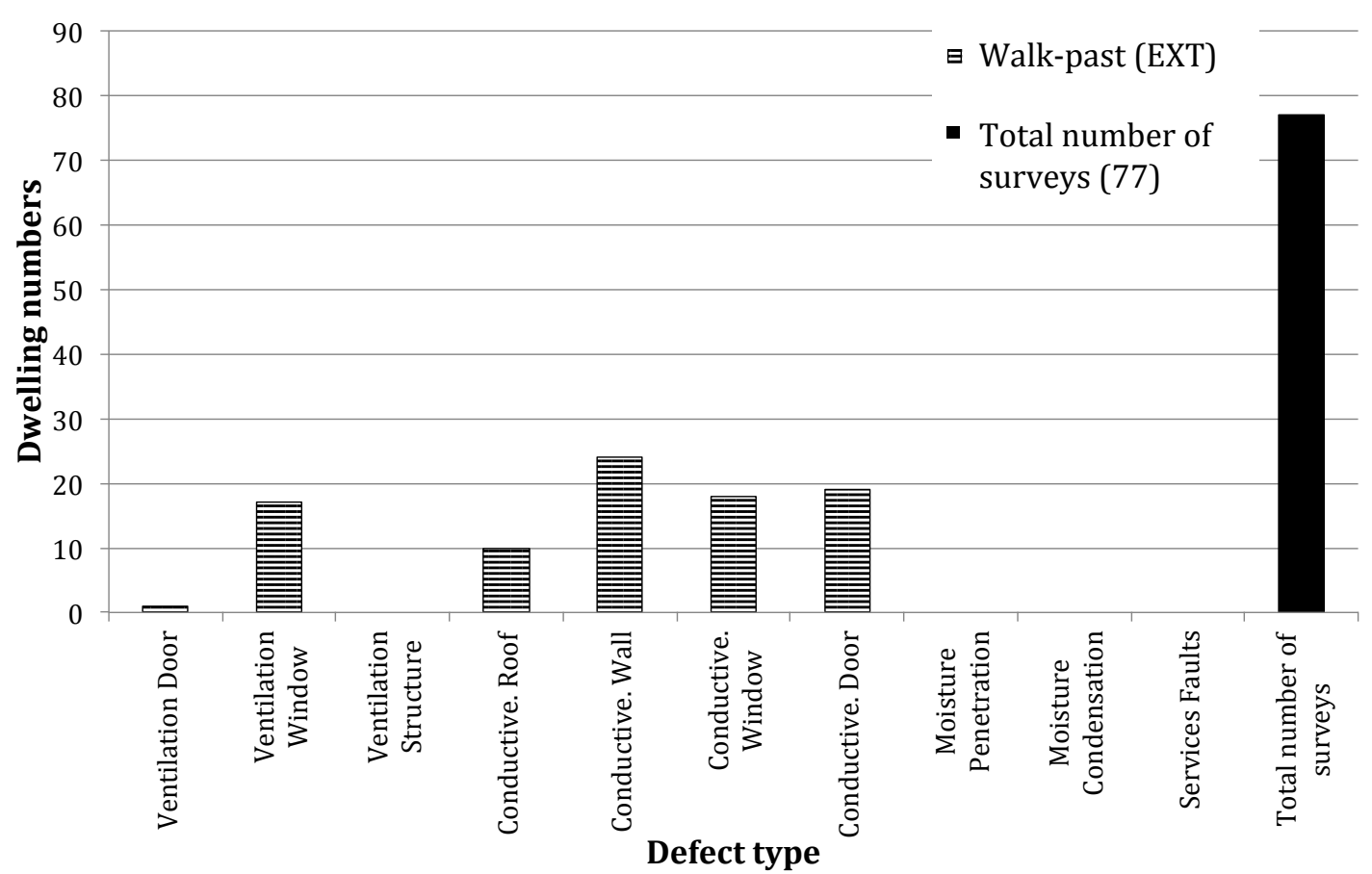

Figure 10. Incidence of thermally significant defect by location and sub-category (Walk-past thermography).

Figure 10 presents a detailed breakdown of the occurrence of potential building defects detected by location and specific sub-category. Compared with the total number of buildings surveyed as part of this study, it is clear that few potential building defects were detected during the walk-past surveys. Further observations from these findings included:

- The vast majority (94\%) of all ventilation heat loss defects came from windows, whilst none were detected from structural draughts. This might have been due to the increased number of windows compared with doors, and common weaknesses found at the seal between windows and frames.

- Conductivity heat losses were the most common source of potential building defect. However, heat loss from roofs was less common than conductivity heat losses from walls, windows and doors. The likely explanation for this is the acute viewing angle (and emissivity problems) that the camera was at relative to a pitched roof and construction of the roof, such as the location of insulation.

Walk-past thermography was found to be particularly useful for defect detection when comparing similar dwellings. By using target comparison methods of qualitative analysis, it became easier to make assumptions based on common patterns of heat loss, such as whether one dwelling had loft insulation compared with another. Figure 11 presents an example discovered during one case study investigation, where comparable dwellings showed similar signs of missing loft insulation. 

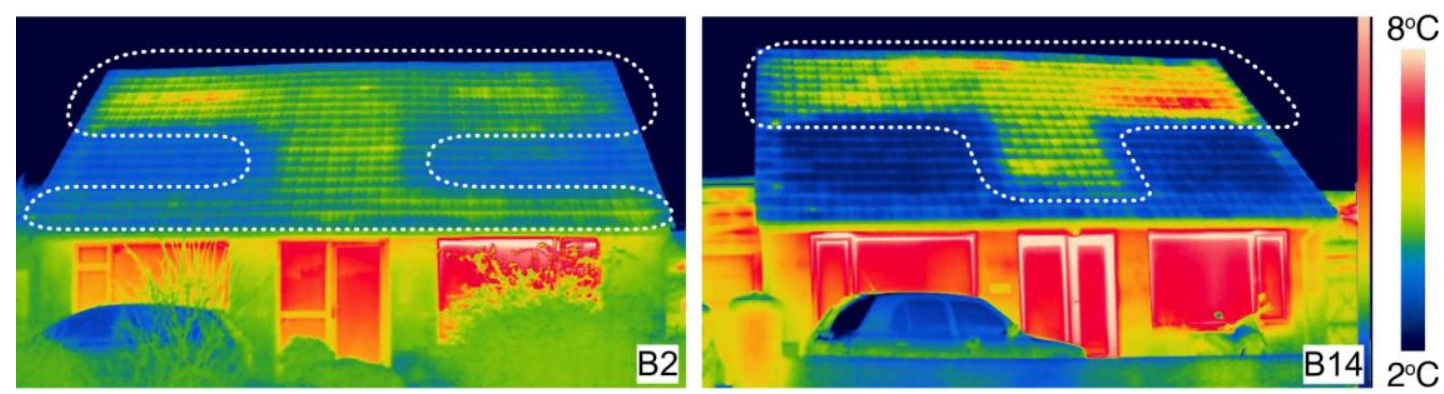

Figure 11. Common trend in heat loss patterns from identical roof constructions.

\subsection{Combined results from two methodologies}

Results from both walk-through and walk-past case studies were combined for cross comparison analysis. Figure 12 illustrates these results by combining figures 7 and 10. Splitting the walk-through thermography results into external (EXT) and internal (INT) locations helps to corroborate the results from the external only walk-past thermography surveys.

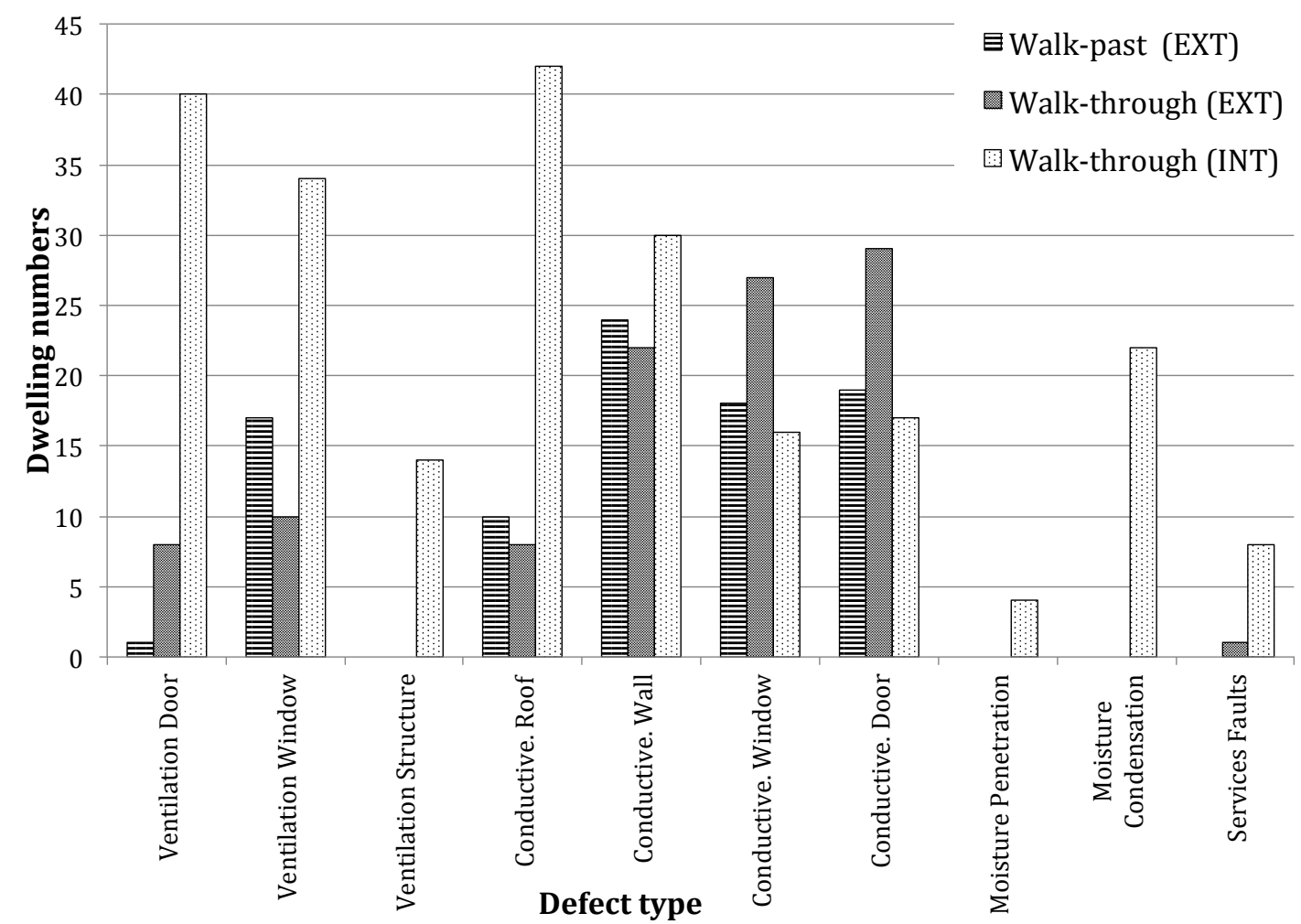

Figure 12. Incidence of thermally significant defect by location and sub-category (for walk-through (internal and external) and walk-past thermography).

Because more buildings were inspected during the walk-past surveys compared with the walk-through surveys, figure 13 presents results from both case studies based on a percentage basis (percentage compared with the total number of dwellings inspected for each methodology). In this figure, it can be seen how $100 \%$ of the dwellings inspected using walk-through thermography presented signs of conductivity defects and $98 \%$ presented signs of ventilation heat loss. Yet during the walk-past surveys, only $64 \%$ showed signs of conductivity heat loss and $22 \%$ ventilation heat losses. 


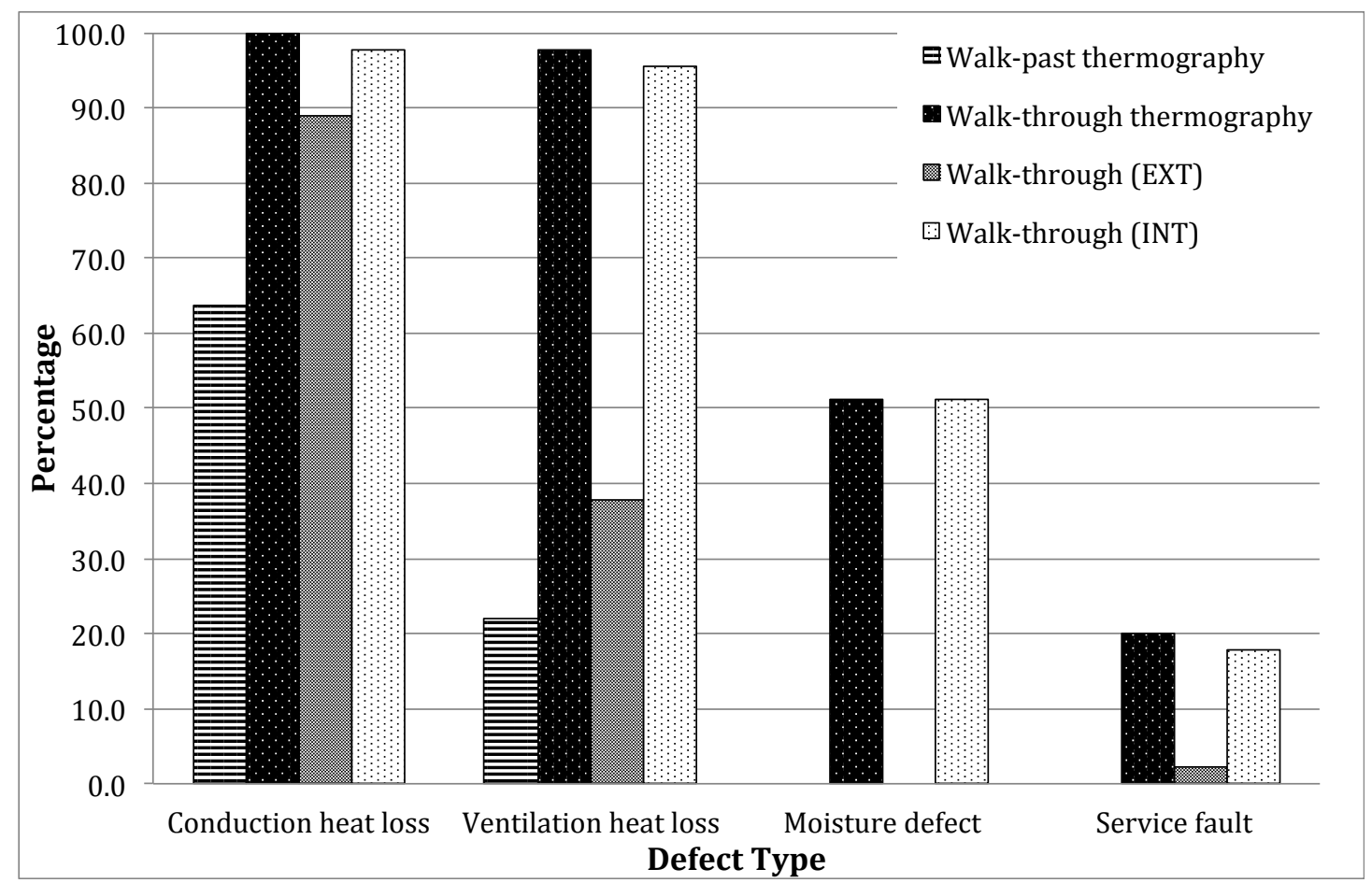

Figure 13. Percentage incidence of thermally significant defect by location and sub-category (for walk-through and walk-past thermography).

\section{Discussion}

By undertaking both walk-through and walk-past thermography methodologies on a variety of dwelling types, it was possible to make a deep comparison of the benefits and limitations between these two methodologies for building defect detection. Key findings included:

- Effectiveness of thermography methods for defect detection,

- The success of defect detection from internal and external sides of a building,

- How case study interaction impacts upon defect detection,

- How different viewing angles impact upon defect detection,

- How changeable climatic conditions impact upon defect detection.

\subsection{Defect detection success}

The most apparent finding was the difference in the quality of defect detection between walk-through and walk-past thermography. It can be seen in figures 12 and 13 how walk-through thermography was found to be very successful at detecting a large number of potential defects. Furthermore these defects were spread across the entire range of defect sub-categories. In contrast however, walk-past thermography had a lower detection rate of building defects. There are two aspects to this finding.

Firstly, there were only two defect groups potentially detected during the four walk-past surveys: conductivity and ventilation heat loss. This meant that other defect groups, such as moisture ingress and condensation, might have been 
missed had they been present within the observed dwellings. Secondly, there were very few clear occurrences of either of these defect types (compared with walk-through thermography on fewer dwellings). Based on these two aspects, it is clear that either the dwellings observed did not have many defects, or that the walk-past methodology missed defects, thereby failing to achieve its basic aim, to detect defects.

Yet there were two defect types that proved to be more detectable using walkpast thermography compared with internal only walk-through thermography. These were conductivity heat losses from doors and windows (Figure 12). Although not necessarily falling under the term 'building defect', excess heat loss from doors and windows could significantly contribute to overall dwelling thermal performance and occupant thermal comfort. As identified in the methodology, direct comparisons between the datasets from the two studies are limited by the difference in case study dwellings. However external walkthrough thermography also proved more successful than internal walk-through thermography at these two defect types. This helps to support the improvement that external thermography inspections can have on these two specific defect types over internal inspections.

One area where walk-past thermography was proven to be relatively successful was through the use of target comparison between similar buildings. Trends in some typical defects were identified using this method of qualitative analysis as shown in figure 11, which illustrates one example of successful target comparison. This successful application might prove useful for very large building stocks, where many buildings are identical in construction. Identifying common weaknesses could help to make standardised repairs or refurbishment programs easier.

\subsection{Internal verses external thermography}

While Holst [40] argues that internal inspections should only be conducted to verify results of external thermography, this work has shown that many internally detected thermal signatures are not always shown during external thermography. For instance, comparing the results of just the walk-through surveys in figure 12 shows that of the 45 dwellings, 93\% displayed signs of conductivity heat loss through a roof when viewed using internal walk-through thermography. Yet only $18 \%$ showed such defect losses under external walkthrough thermography. This would have resulted in 75\% of dwellings (inspected during the walk-through surveys) with roof conductivity losses having their defect missed if an external only walk-through or walk-past methodology had been used alone.

Whilst internal defects were sometimes detectable from the outside as shown in figure 8, there were more circumstances where internal defects were not observable from the outside. A number of scenarios could explain why it might have been difficult to view the same defect on more than one side. One scenario was due to the thickness of construction, which might hinder the conductive flow of heat from inside to outside. For example, the internal heat from a solid stone wall construction dwelling will take longer to manifest a corresponding thermal 
pattern on the outside when compared with an un-insulated timber frame construction, which will probably show signs of heat loss a lot faster. This might have been compounded by the length of time the internal heating system had been on prior to the thermographic survey. Since both of these methodologies record only one moment in time, this issue might have led to misinterpretations or defects being completely missed. Another scenario might have been due to uncontrollable or unknown variances in climatic conditions (such as solar exposure or precipitation) during the hours prior to a survey.

Yet, for both of these scenarios, it is difficult to definitively ascertain what might be adversely affecting the thermal signature of defects when viewed externally. This limitation adds support to arguments by others [12] who caution against the use of quantitative analysis for external thermography.

In summary, internal walk-through thermography was found to be much more successful at detecting a broader range of thermally significant building defects in more buildings than found during the external walk-through and walk-past inspections. Although proving successful at the detection of conductivity heat loss from doors and windows, external thermography did not detect many defects. On this basis, the research in this paper verifies Vollmer \& Möllmann's [1] caution against using external thermography alone. The thermal images collected during walk-past thermography only provide a basic overview of the front elevation, which may explain some of the building defects but is likely to have missed more. This supports assertions by Berry [27] who highlights numerous uncertainties due to not knowing occupancy behaviour and features of the other elevations. Had internal inspections been undertaken on the walkpast case study dwellings, it would seem reasonable to assume that a greater number of potential defects would have been discovered using internal walkthrough thermography.

\subsection{Interaction with case studies}

One significant difference between walk-through and walk-past thermography was the interaction made with the case study (Buildings and occupants).

Walk-through thermography relied upon case study interaction. The thermographer entered the dwelling and engaged with its occupants. This benefited the inspection procedure by helping to better understanding internal climatic conditions and particular thermal features such as the location of boilers etc. Utilising the real-time benefit of modern thermal cameras, real-time discussions on potential defects with householders was found to help guide the thermographer in their analysis of the dwelling. Thermographers were also able to make use of their senses (such as smell) to detect mould and damp for example. Yet such interaction added to the length of the survey time, which took up to 60 minutes to complete.

Conversely walk-past thermography did not require case study interaction. By only inspecting external elevations, this methodology was found to be much faster than walk-through thermography, with inspections taking on average 7 minutes to complete. Based on this timing, and providing all dwellings are in 
close proximity to each other, this survey methodology would permit eight dwellings to be surveyed in one hour. If a survey session lasts from between $8 \mathrm{pm}$ and 1 am ( 6 hours duration), approximately 51 dwellings could be inspected using walk-past thermography. In contrast a maximum of 6 dwellings could be imaged in the same time using walk-through thermography.

Although inspecting dwellings without making contact with occupants can be viewed as a benefit, this is also found to be a limitation. When inspecting a dwelling, it became difficult to ascertain whether dwellings were currently occupied and what the internal heating program was. One method to ascertain whether the dwelling was currently occupied was to look for signs such as lights being on. Figure 14 presents an example of this where a photograph was recorded at the same time as the thermal image. In this example, each floor corresponds to a different tenanted flat. Whilst the photograph helps to indicate occupancy on the ground and first floor, it cannot confirm whether someone was home on the second floor and using rooms at the rear, rather than the front of the dwelling. This photo also cannot confirm the numbers of people (whether one person was there or if there was a party with lots of people) within the flats, the internal air temperature or whether the heating had been on for the whole day, a couple of hours or a couple of minutes prior to the survey. Even if the second floor flat was unoccupied, the heating program might have been on for longer and to a higher temperature than one of the illuminated flats below.
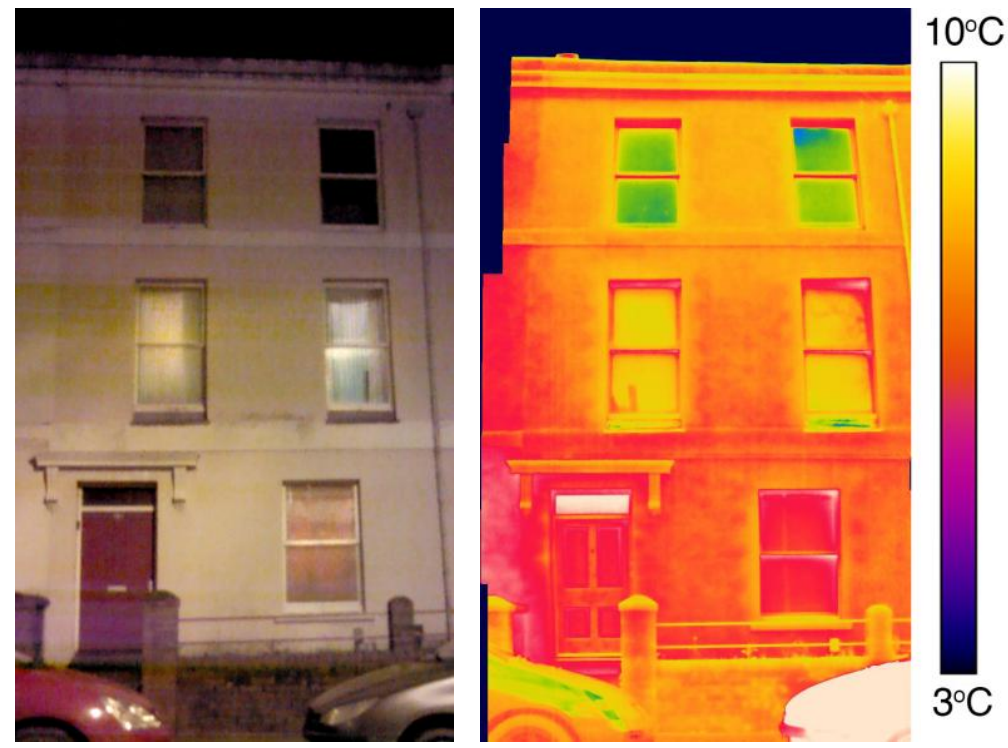

Figure 14. Photograph showing dwelling lighting to help indicating occupancy during analysis of thermal image.

Without this information it proved difficult to ascertain whether one building or part of a building was better insulated than another, or whether one building had a defect and another did not. This is due to variations in heat transfer through the different construction elements. For example, if the heating had only just been turned on in a dwelling that showed signs of occupancy, it is possible that there will be an insufficient temperature difference between inside and outside to clearly show signs of potential defects. 
The absence of this information also questioned the success of walk-past thermography at correctly detecting adverse heat loss from building components, especially windows and doors, which due to their thickness and construction portrayed signs of conductivity better than other components. As part of a project investigating air-tightness testing in dwellings, Kalamees [41] used occupant questionnaires to enquire about dwelling construction and occupant thermal habits. This might be one method for better understanding dwelling occupancy following a walk-past thermography survey.

\subsection{Comparison of methodology viewing angles}

Referring back to point 5.2 and figure 12, one reason why roof conductivity losses were more difficult to detect externally compared with internally is that most of the roofs inspected were pitched and comprised of slate. When viewed at an angle, where the camera is at street level, the relatively low emissivity $(0.85$ compared with many building materials that are in the 0.90s) and specular finish of slate reflects the sky more noticeably than other materials and will degrade the thermal signature of potential defects. Although viewing angle is an important reason why roof defects are less likely to be detected externally, another factor is the roof construction. Since loft insulation is traditionally placed along the top floor ceiling between the joists rather than lining the pitched roof, small defects in the insulation are more difficult to detect using external thermography. As this method of construction is commonly used, it can be argued that the results in figure 12 with regards to roof defects align with what would be expected.

Whilst the limitation of acute roof angles could be mitigated by positioning the camera at less oblique angles to the roof surface, such as through using an extendable/telescopic mast. Even then, potential roof defects may not be detected due to variations in construction methods. Therefore internal inspections should be utilised for roof defects wherever possible.

One of the key advantages to walk-through thermography is the dynamic way in which the thermal camera can be used [42]. A well known attribute of modern day thermal cameras, the research in this paper illustrated how the thermographer could move relatively quickly around a dwelling inspecting building features from different angles and distances dependent on a given situation. This approach was made even more effective through utilising the camera's ability to provide real-time feedback and analysis. By viewing potential defects from multiple angles, sides and at various distances, a much better understanding of the nature and cause could be inferred.

In contrast, walk-past thermography was constrained by the frequently perpendicular fixed viewpoint that the thermal camera was to the building elevation, which negated the dynamic feature. This constraint comprised of multiple aspects, including single elevation analysis, limitations with low emissivity materials and spatial resolution diminished due to distance. Experience of these within the case studies supported Berry's [28] critique on pass-by thermography. 


\section{Single elevation analysis}

One of the key characteristics of walk-past thermography is single elevation observation. This elevation is usually the side of the dwelling facing the street. All other external elevations are not included. Because of this factor, only one part of the case study dwelling was inspected. Therefore, if building defects were present elsewhere on the dwelling, these would have been missed.

\section{Spatial resolution diminished due to distance}

As reported in the methodology, distances of up to $20 \mathrm{~m}$ were commonly required to capture entire building elevations within the camera's FOV. Such distances to the target surface pose limitations to spatial resolution. Based on the thermal camera specifications listed in figure 1, defects with a thermal signature smaller than $42 \times 42 \mathrm{~mm}$ in any direction might not have been adequately detected at this distance due to them falling out with the MIFOV measurement performance of the sensor and might have been missed or misinterpreted. This is unlike walk-through thermography, where the thermographer was able to move closer for more detailed inspection. The inspections in this paper utilised a relatively high specification thermal camera. Should a lower specification thermal camera be used, larger thermal signatures at similar distances would be missed.

\section{Limitations with low emissivity materials}

The need to capture the whole façade within one fixed view/thermal image means that reflections from low emissivity materials such as glazing and metal claddings are more difficult to mitigate during pass-by thermography compared with walk-through thermography. This is because of the fixed view point, which makes adjusting the camera angle to remove reflected radiation sources (such as the thermographer) more difficult than the dynamic methodology of walkthrough thermography, where time can be taken to view low emissivity surfaces from multiple angles, thereby mitigating against the effects from reflected radiation sources.

When conducting external thermography at night it is possible for the thermographer to visually overlook materials with a low emissivity. When viewed with the thermal camera, contrasting thermal signatures from unexpected low emissivity surfaces might be mistaken as defects. It is therefore recommended that all external thermographic images be supported with visual photographic inspections (preferably taken during the day) to identify material differences, which will help with thermal image analysis.

\subsection{Changeable climatic conditions}

Since both methodologies make use of a single point in time, image capture methodology [4], the effects of transient climatic conditions were much harder to understand and mitigate compared with using a more lengthy methodology such as time-lapse thermography. This was a limitation for both walk-through and walk-past thermography, since occasionally conditions changed over short periods of time. This will have impacted upon the results from one image to the next. 
However the extent to which this limitation impacted upon internal inspections was lesser than experienced with external thermography. For example wind, rain and night sky radiant cooling effected internal inspections less than encountered during all external inspections. Internally, the key climatic criterion was found to be the temperature difference between internal and external spaces. This needed to be at least $10 \mathrm{~K}$ [31].

While weather conditions may change from one survey to the next (day to day), making it difficult to compare similar dwellings from different survey sessions, some of the weather conditions also changed during the survey period. Changes in cloud cover were one such transient weather condition, which were particularly noticeable during all external inspections. For example, as clouds moved across the sky, the first image reflected a cloudy sky, while the cloud might have passed by the time of the second image. The difference between the two conditions could have significantly affected image comparisons given the extremely low temperatures of about 223.15K [12] that a clear sky can emit compared with a cloudy sky (measured at approximately 267.05K). This was particularly problematic during walk-past thermography, where contrasting results between neighbouring dwellings might have been due to a change in the cloud movement. Other transient conditions such as precipitation, wind and solar exposure might have an impact on defect detection using target comparison methods of qualitative analysis.

\section{Conclusion}

This paper has compared a walk-past thermography methodology with traditional walk-through thermography for qualitative defect detection on residential buildings. Key results included:

- Inspections were much faster using walk-past thermography (up to 10 minutes long) compared with walk-through thermography (up to 60 minutes long).

- Trends in defects were identified in dwellings with matching constructions using walk-past thermography.

- The number and variety of detectable defects found using walk-past thermography were inferior to those detected during walk-through thermography.

- A broad range of defects were detected using walk-through thermography.

- Only conductivity and ventilation heat losses were observed using walkpast thermography.

- A greater number of potential defects were detected using internal thermography compared with external walk-through or walk-past inspections. This finding underlines the importance of utilising internal as well as external thermography for all surveys.

In addition to the commonly known constraints to building thermography, several additional limitations were identified as key contributors to the poorer defect detection rate of walk-past thermography compared with walk-through 
thermography. These comprised of unknown occupancy behaviours, single elevation only analysis, fixed viewing angle, variable elevation orientations, diminished spatial resolution and transient climatic conditions from one dwelling to the next.

These limitations were mitigated during walk-through inspections, where more dynamic and occupant interactive methods made defect detection much more successful.

Despite being a quicker and cheaper methodology compared with walk-through thermography, the findings from this paper question the overall value of walkpast thermography as a survey methodology for meeting its basic objective: to detect defects. On this basis, if defection in buildings is the primary objective for a survey, then walk-through thermography should be selected in preference to walk-past thermography. Yet being 55 to 95 times cheaper than walk-through thermography, a pass-by methodology could hold some value if it is only utilised as a motivational tool, to encourage occupants to think thermally and undertake thermal retrofits or as a tool to find large areas of poorer building stock.

Although this paper studied qualitative rather than quantitative analysis, it can be inferred from these results that since qualitative defect detection using walkpast thermography was found to be less successful than walk-through thermography, quantitative analysis using a pass-by thermography methodology is unlikely to be accurate. Since apparent surface temperature readings will be affected by the identified limitations, it is also not possible to make generalised statements (quantitative or qualitative) on the presence of defects or overall thermal conductivity based on the information from a single elevation.

The research in this paper forms part of a larger investigation into new and emerging thermography methodologies as a means of improving defect detection in buildings.

\section{Acknowledgements}

The writing of this manuscript has been facilitated through the eViz project, which is funded by the Engineering and Physical Sciences Research Council (EPSRC) under the Transforming Energy Demand in Buildings through Digital Innovation (TEDDI) (grant reference EP/K002465/1). Case studies were obtained from the DCH Group and as part of the Eden Project and DECC (Department of Energy \& Climate Change) funded Cornwall Together Phase 2 project [29].

\section{References}

[1] M. Vollmer, K.-P. Möllmann, Infrared Thermal Imaging. Fundamentals, Research and Applications, Wiley-VCH, Weinheim, Germany, 2010.

[2] B.R. Lyon, G.L. Orlove, A Brief History of 25 Years (or more) of Infrared Radiometers, in: E. Cramer, X.P. Maldague (Eds.) Thermosense XXV, SPIE Orlando, FL, 2003, pp. 17-30.

[3] E. Edis, I. Flores-Colen, J. de Brito, Quasi-quantitative infrared thermographic detection of moisture variation in facades with adhered ceramic cladding using 
principal component analysis, Building and Environment 94, Part 1 (2015) 97108.

[4] M. Fox, D. Coley, S. Goodhew, P.D. Wilde, Thermography methodologies for detecting energy related building defects, Renewable and Sustainable Energy Reviews 40 (2014) 296 - 310.

[5] M. Fox, D. Coley, S. Goodhew, P.D. Wilde, Time-lapse thermography for building defect detection, Energy and Buildings 92(0) (2015) 95-106.

[6] M. Schwoegler, Thermal Imaging of Cambridge, MA in the News. <www.thesnellgroup.com>, 2011 (accessed 10/10/2012.).

[7] ASTM, Standard Practice for Thermographic Inspection of Insulation Installations in Envelope Cavities of Frame Buildings, in: American Society for Testing and Materials (ASTM) (Ed.) ASTM, West Conshohocken, PA, USA, 1997. [8] RESNET, Interim Guidelines for Thermographic Inspections of Buildings, Residential Energy Services Network2012.

[9] BSi, Thermal performance of buildings - Qualitative detection of thermal irregularities in building envelopes - Infrared method (ISO 6781:1983 modified), BSi1999.

[10] G.R. Stockton, Applications for Infrared Thermography as an NDT Method for Buildings, IV Conferencia Panamericana de END, Buenos Aires, 2007.

[11] J.R. Kominsky, J.S. Luckino, T.F. Martin, Passive Infrared Thermography-A Qualitative Method for Detecting Moisture Anomalies in Building Envelopes, Tedford \& Pond, 2007.

[12] C. Pearson, Thermal Imaging of building fabric, BISRA Guide BG39 (2011).

[13] UKTA, Building Thermography, UK Thermography Association2007.

[14] M.C. Gillott, D.L. Loveday, J. White, C.J. Wood, K. Chmutina, K. Vadodaria, Improving the airtightness in an existing UK dwelling: The challenges, the measures and their effectiveness, Building and Environment 95 (2016) 227-239. [15] M. Fox, D. Coley, S. Goodhew, P.D. Wilde, Comparing Transient Simulation with Thermography Time Series, Building Simulation and Optimization Conference, IBPSA England, Loughborough, UK, 2012, p. 8.

[16] T. Taylor, J. Counsell, S. Gill, Combining thermography and computer simulation to identify and assess insulation defects in the construction of building fac, ades, Energy and Buildings 76 (2014) 130-142.

[17] K. Westerhold, Is your Building Thermography Survey telling you what you want to know? <http://www.thebestoftech.com>, 2013 (accessed 29/07/2013.2013).

[18] A. Smale, Thermal Imaging Survey. <www.expert-energy.co.uk>, 2014 (accessed 03/12/2014.).

[19] Expert Energy, Thermal Imaging Survey. Prices. <http://expertenergy.co.uk/thermal_imaging_survey.html>, 2015 (accessed $11 / 12 / 2015.2015$ ).

[20] L.N. Phan, Automated Rapid Thermal Imaging Systems Technology, Department of Mechanical Engineering, Massachusetts Institute of Technology, Massachusetts 2012, p. 276.

[21] Essess, Essess. Thermal Technology. Scale. <www.essess.com>, 2015 (accessed 25/02/2015.).

[22] J.P. Miller, N. Singh, Kinetic Super-Resolution Long-Wave Infrared (KSR LWIR) Thermography Diagnostic for Building Envelopes, in: T.U.S.A.E.R.a.D.C. 
(ERDC) (Ed.) Environmental Security Technology Certification Program (ESTCP), Washington, DC, 2015.

[23] D. Olanoff, Inside Google Street View: From Larry Page's Car To The Depths Of The Grand Canyon. <www.techcrunch.com>, 2013 (accessed 08/04/2013.). [24] IRT surveys, 2013 the most important year for energy efficiency in Social Housing - the move to Green Deal/ECO + £5 Energy Efficiency Surveys, Category: Energy Efficiency, IRT surveys, 2013.

[25] S. Currie, SFHA Carbon Portal -A Housing Associations Perspective, Clyde Valley Housing Association, 2012.

[26] D.L. Chandler, The big picture on energy loss. MIT system, tested in Cambridge, gives comprehensive view of energy inefficiency across large areas. <www.web.mit.edu/>, 2011 (accessed 10/10/2012.).

[27] B. Berry, Thermography of buildings (myth no 8), Building Thermography, Thermal Vision, Dunboyne, Co Meath, 2014a.

[28] B. Berry, Thermography of buildings (myth no 9), Building Thermography, Thermal Vision, Dunboyne, Co Meath, 2014b.

[29] J. Goodhew, M. Fox, C. Boomsma, S. Pahl, S. Goodhew, Thermal Imaging Cornwall 2013, Cornwall Together Phase II, Pymouth University, Plymouth, 2013, p. 47.

[30] C.J. Drew, M.L. Hardman, J.L. Hosp, Designing and Conducting Research in Education, SAGE Publications, Inc Thousand Oaks, California, USA, 2008.

[31] N.J. Walker, Volume one - Principles and Practice, BINDT, Northampton, UK, 2004.

[32] FLIR, FLIR Tools+, FLIR Systems, 2014.

[33] BINDT, CM/GEN - Specific Requirements for Qualification and PCN Certification of Condition Monitoring and Diagnostic Personnel for Infrared Thermography, BINDT Certification Services Division, Northampton, 2009, p. 20. [34] D. Marshall, D. Worthing, R. Heath, N. Dann, Understanding Housing Defects, 4th edition ed., Routledge, Abingdon, Oxon, 2014.

[35] J. Douglas, E.A. Noy, Building Surveys \& Reports, 4th Edition ed., WileyBlackwell, Chichester, UK, 2011.

[36] C.A. Balaras, A.A. Argiriou, Infrared thermography for building diagnostics, Energy and Buildings 34(2) (2002) 171-183.

[37] FLIR, Thermal Imaging Guidebook for Building and Renewable Energy Applications, FLIR Systems AB2011.

[38] R. Walker, S. Pavía, Thermal performance of a selection of insulation materials suitable for historic buildings, Building and Environment 94, Part 1 (2015) 155-165.

[39] D.J. Titman, Applications of thermography in non-destructive testing of structures, NDT\&E International 34, Elsevier Science Ltd, 2001.

[40] G.C. Holst, Common sense approach to thermal imaging, SPIE - The International Society for Optical Engineering, Bellingham, Washington USA, 2000.

[41] T. Kalamees, Air tightness and air leakages of new lightweight single-family detached houses in Estonia, Building and Environment 42 (2007) 2369 - 2377. [42] ITC, Thermography Level 1 Course Manual, Infrared Technology Centre, FLIR systems AB, Stockholm Sweden, 2006. 